\title{
Complete mitogenome of asiatic lion resolves phylogenetic status within Panthera
}

\author{
Snehal B Bagatharia*, Madhvi N Joshi, Rohan V Pandya, Aanal S Pandit, Riddhi P Patel, Shivangi M Desai, \\ Anu Sharma, Omkar Panchal, Falguni P Jasmani and Akshay K Saxena
}

\begin{abstract}
Background: The origin, evolution and speciation of the lion, has been subject of interest, debate and study. The present surviving lions of the genus Panthera comprise of eight sub-species inclusive of Asiatic lion Panthera leo persica of India's Gir forest. Except for the Asiatic lion, the other seven subspecies are found in different parts of Africa. There have been different opinions regarding the phylogenetic status of Panthera leo, as well as classifying lions of different geographic regions into subspecies and races. In the present study, mitogenome sequence of $P$. leo persica deduced, using lon Torrent PGM to assess phylogeny and evolution which may play an increasingly important role in conservation biology.

Results: The mtDNA sequence of P. leo persica is 17,057 bp in length with $40.8 \%$ GC content. Annotation of mitogenome revealed total 37 genes, including 13 protein coding, 2 rRNA and 22 tRNA. Phylogenetic analysis based on whole mitogenome, suggests Panthera pardus as a neighbouring species to $P$. leo with species divergence at $\sim 2.96$ mya.

Conclusion: This work presents first report on complete mitogenome of Panthera leo persica. It sheds light on the phylogenetic and evolutionary status within and across Felidae members. The result compared and evaluated with earlier reports of Felidae shows alteration of phylogenetic status and species evolution. This study may provide information on genetic diversity and population stability.
\end{abstract}

Keywords: Asiatic lion, Big cats, Panthera leo persica, Mitogenome, Ion torrent, Phylogeny, Evolution, Felidae, Divergence time

\section{Background}

Five big charismatic cats: Panthera leo (lion), Panthera tigris (tiger), Panthera onca (jaguar), Panthera pardus (leopard) and Uncia uncia (snow leopard) have been placed taxonomically in Pantherinae subfamily. They have been drawing attention of biologists due to important ecological roles [1]. Consequently, extensive information is available on their natural history, morphology, behaviour, reproduction, evolutionary history and population genetic structure, which provides a rich basis for interpreting genetic data [2]. The information is still not adequate to overcome their highly threatened status. Hence, molecular study is vital to further explore the genetic information which can be helpful for conservation.

\footnotetext{
* Correspondence: snehalbagatharia@hotmail.com

Gujarat State Biotechnology Mission, Department of Science and

Technology, Government of Gujarat, Block-11, 9th Floor, Udyog Bhavan,

Sector 11, Gandhinagar 382 017, Gujarat, India
}

Panthera leo has two geographically isolated populations; Panthera leo leo (African lion), and Panthera leo persica (Asiatic lion) [3]. The Asiatic lion population is accorded endangered species status under the Indian Wildlife Protection Act, consisting only 411 wild animals [4]. This population exist in and around Gir forest in the southwest part of Saurashtra region in the State of Gujarat, India. Presence of geographically confined single population having its origin from small nucleus group and constituting single gene pool, raises concerns about genetic diversity in Asiatic lion population. Morphological and molecular approaches like allozyme study [5] microsatellite analysis [6], protein markers and mitochondrial $12 \mathrm{~S}$ gene [7] have been used to unveil the evolutionary history of this species. Earlier efforts have been made to undertake the population study of Panthera leo persica (NCBI Taxonomy ID: 83386) and other allied
C Biomed Central

(C) 2013 Bagatharia et al.; licensee BioMed Central Ltd. This is an Open Access article distributed under the terms of the Creative Commons Attribution License (http://creativecommons.org/licenses/by/2.0), which permits unrestricted use, distribution, and reproduction in any medium, provided the original work is properly cited. 
species [8] to establish phylogenetic status. However, it has been found to be perplexing [7].

For the last decade, mitochondrial DNA has been one of the most commonly used molecular marker in vertebrates for studying phylogeny and evolutionary relationships [9] among closely related species and subspecies [10]. It can reveal evolutionary relatedness and elucidate large numbers of genome-level characteristics, such as relative arrangements of genes [11]. It also has a great importance for the molecular identification of species. Cytochrome b and Cytochrome oxidase subunit I [12] are mitochondrial genes widely used for molecular identification of animals. Further, key mitochondrial features - a lack of recombination, essentially maternal inheritance, high evolutionary rate, compact size, and conserved gene order [9], have led to its wide spread use.

Earlier, phylogenetic relationship of the genus Panthera was studied using morphological, biochemical as well as molecular characters but it is still debatable and troublesome because of large disparities between these studies. The difficulty in resolving their phylogenetic relationships is a result of (i) a poor fossil record, (ii) recent and rapid radiation during the Pliocene, (iii) individual speciation events occurring within less than 1 million years (iv) probable introgression between lineages following their divergence [13]. Phylogenetic relationship and position of Panthera leo, amongst the genus Panthera, has some knowledge gaps. The present study aims to provide some insights through the complete mitogenome of the Asiatic lion.

\section{Results and discussion}

Mitochondrial genome sequence of any subspecies of Panthera leo, is not reported in literature. Present study describes sequencing of complete mitogenome of Asiatic Lion ( $P$. leo persica) with the use of next generation sequencing technology on Ion Torrent ${ }^{\text {PGM }}$ platform. The relationship of lion subspecies with other Felidae species and their evolutionary status has also been described on the basis of comparative analysis of mitogenomes.

\section{Base composition of mitochondrial genome of Panthera leo persica}

The complete mitogenome sequence of $P$. leo persica is 17,057 bp in length (GenBank accession No: KC834784), which is larger than Panthera pardus $(16,964)$ and Uncia uncia $(16,773)$. The base composition of mitogenome of P. leo persica is A, 5445 bp (31.92\%); T, 4650 bp (27.26\%); C, 4492 bp (26.33\%); G, 2470 bp (14.48\%); A+T 9939 bp (59.18\%), G+C 6879 (40.81\%). Base A is highest among the 4 bases; $G$ is the lowest. Features of lion mitogenome were compared with genomes of Felidae family. The genome size varies from $16773 \mathrm{bp}$ to $17153 \mathrm{bp}$ mainly because of variation in control region length. GC content of all the genomes is ranging from $39.37 \%$ to $41.19 \%$ (Table 1).

\section{Structure of mitogenome of Panthera leo persica}

Location of the mitochondrial genes were deduced, using online annotation server MITOS [14]. Complete mitogenome contained 37 genes which include 13 protein coding genes, 2 rRNA genes, 22 tRNA genes and the control region (Figure 1). Gene order and origin of reading frame of all protein coding genes were identical to Carnivora. Major difference in $P$. leo persica mitogenome was observed in size of the control region $(1,603 \mathrm{bp})$.

Transfer RNA was annotated in a single letter amino acid code. OHR and OLR represent the replication origins of $\mathrm{H}$ strand and $\mathrm{L}$ strand. Except for ND6, all protein coding genes were $\mathrm{H}$ strand encoded. Position of genes and control regions (CR) were indicated with Arabic numerals (Table 2).

\section{Proteins and codons}

The studied mitogenome comprise of 13 protein coding genes $(11,364 \mathrm{bp})$ and share $66.62 \%$ of total genome. These genes encode 3788 amino acids (Table 2). The longest gene was ND5 (1815 bp) and the shortest gene was ATP8 (198 bp). The start and termination codons appeared universal among species. ATG was commonly used as start codon for all the genes except ND2, ND5, COX1, ND6 and ND3, which used ATA, ATT and ATC, respectively. TAA was commonly found as stop codon while Cyt b ended with AGA. Termination of Cyt b gene with AGA, is typical for mammalian species [15-17] which is distinct from others such as amphibians [18], reptiles $[19,20]$, Aves [21] and Nematoda [22]. ND3, ND4, ND2 and COX3 have incomplete stop codons. These incomplete termination codons are common in metazoan mitogenome and can be converted into complete ones by poly A after transcription (TAA) [23].

\section{tRNA and rRNA}

Total 22 tRNA genes were found in mitogenome of $P$. leo persica, amongst these tRNA ${ }^{\text {ser }}$ and tRNA ${ }^{\text {leu }}$ had two termination codons (Table 2). Length of the tRNA genes in vertebrates is reported from 59 to 75 bp [24]. In this study, the shortest tRNA is tRNA ${ }^{\text {ser }}$ (59 bp) and longest is tRNA $^{\text {leu }}(75 \mathrm{bp})$. Cloverleaf secondary structure of tRNAs of this genome was predicted, out of which representative structures of $\mathrm{tRNA}^{\text {phe }}$ and $\mathrm{tRNA}^{\text {ser }}$ are shown (Figure 2). Out of all tRNAs, tRNA ${ }^{\text {ser }}$ lacked the "DHU" arm [25]. The location of 12S rRNA (964 bp) was between tRNA $^{\text {phe }}$ and tRNA ${ }^{\text {val }}$ and 16S rRNA (1576 bp) was between tRNA $^{\text {val }}$ and tRNA ${ }^{\text {leu }}$. 
Table 1 General mitogenome features of Felidae family

\begin{tabular}{lcccccc}
\hline Species name & Common name & NCBI Taxonomy ID & Accession no. & CR Length & GC \% & Genome length \\
\hline Acinonyx jubatus & Cheetah & 32536 & NC_005212 & 1602 & 39.37 & 17047 bp \\
Prionailurus bengalensis euptilurus & Amur leopard cat & 300877 & NC_016189 & 1547 & 39.55 & $16990 \mathrm{bp}$ \\
Puma concolor & Puma & 9696 & NC_016470 & 1706 & 39.78 & $17153 \mathrm{bp}$ \\
Felis catus & Domestic cat & 9685 & NC_001700 & 1559 & 40.33 & $17009 \mathrm{bp}$ \\
Panthera leo persica & Asiatic lion & 83386 & KC834784 & 1603 & 40.8 & $17057 \mathrm{bp}$ \\
Uncia uncia & Snow leopard & 29064 & NC_010638 & 1318 & 40.97 & $16773 \mathrm{bp}$ \\
Lynx rufus & Bobcat & 61384 & NC_014456 & 1606 & 41.01 & $17056 \mathrm{bp}$ \\
Panthera pardus & Leopard & 9691 & NC_010641 & 1514 & 41.11 & $16964 \mathrm{bp}$ \\
Panthera tigris & Tiger & 9694 & NC_010642 & 1537 & 41.14 & $16990 \mathrm{bp}$ \\
Neofelis nebulosa & 61452 & NC_008450 & 1400 & 41.15 & $16844 \mathrm{bp}$ \\
Panthera tigris amoyensis & Clouded leopard & NC_014770 & 1550 & 41.19 & $17001 \mathrm{bp}$ \\
\hline
\end{tabular}

\section{Control region}

The control region of the mitogenome of $P$. leo persica is located between tRNA ${ }^{\text {Pro }}$ and tRNA ${ }^{\text {Phe }}$. It contains only promoters and regulatory sequences for replication and transcription, but no structural genes (Figure 3). CR is divided into three parts: the left domain (16,321-16,808bp) which includes the hyper variable segment HVS-1, the central conserved region (CCR) of $529 \mathrm{bp}$, and the right domain of (280-867 bp), which include HVS-2. Further the repetitive sequence RS-2 is in the left domain located at the 5 ' end. It consists of long repetitive motif of about 80 bp which is repeated 4.7 times (3'-CCCCATGAA TATTAAGCATGTACAGTAGTTTATATATATTACATA AGGCATACTATGTATATCGTGCATTAACTGCTTG T-5'). RS-3 is located in right domain at 3' end. It consists of short repeat units of $14 \mathrm{bp}$ which is repeated 20 times (3'-ACACGTACACACGT-5'). RS-3 is highly variable in the arrangement of specific motifs and is

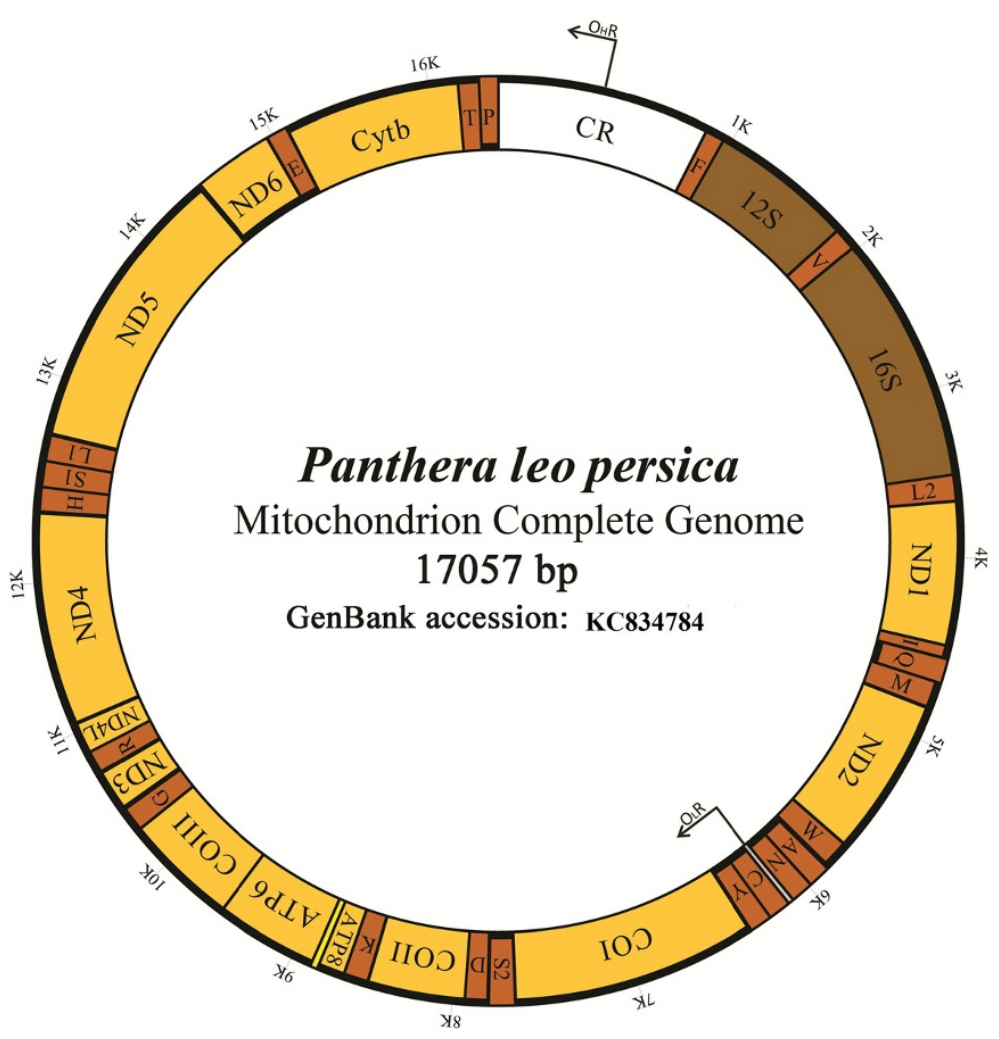

Figure 1 Complete mitochondrial genome organization of Panthera leo persica. 
Table 2 Location of features in the mitochondrial DNA of Panthera leo persica

\begin{tabular}{|c|c|c|c|c|c|c|}
\hline \multirow[t]{2}{*}{ Name } & \multicolumn{2}{|c|}{ Position } & \multicolumn{2}{|c|}{ Codon } & \multirow[t]{2}{*}{ Chain } & \multirow[t]{2}{*}{ Length } \\
\hline & Start & Stop & Start & Stop & & \\
\hline $\operatorname{trnF}$ (gaa) & 868 & 939 & & & $\mathrm{H}$ & 72 \\
\hline rrns & 940 & 1903 & & & $\mathrm{H}$ & 964 \\
\hline $\operatorname{trnV}(\operatorname{tac})$ & 1902 & 1970 & & & $\mathrm{H}$ & 69 \\
\hline $\mathrm{rrnL}$ & 1969 & 3544 & & & $\mathrm{H}$ & 1576 \\
\hline $\operatorname{trnL2(taa)}$ & 3545 & 3619 & & & $\mathrm{H}$ & 75 \\
\hline nad1 & 3622 & 4572 & ATG & TAA & $\mathrm{H}$ & 951 \\
\hline trnl(gat) & 4578 & 4646 & & & $\mathrm{H}$ & 69 \\
\hline $\operatorname{trnQ}(\operatorname{ttg})$ & 4644 & 4717 & & & $L$ & 74 \\
\hline trnM(cat) & 4719 & 4787 & & & $\mathrm{H}$ & 69 \\
\hline nad2 & 4782 & 5819 & ATA & TAG & $\mathrm{H}$ & 1038 \\
\hline $\operatorname{trnW}$ (tca) & 5830 & 5898 & & & $\mathrm{H}$ & 69 \\
\hline $\operatorname{trn} A(\operatorname{tgc})$ & 5914 & 5982 & & & $\mathrm{~L}$ & 69 \\
\hline $\operatorname{trnN}(\mathrm{gtt})$ & 5984 & 6056 & & & $L$ & 73 \\
\hline $\operatorname{trnC}(g c a)$ & 6090 & 6154 & & & $\mathrm{~L}$ & 65 \\
\hline $\operatorname{trn} Y(g t a)$ & 6155 & 6220 & & & $L$ & 66 \\
\hline $\operatorname{cox} 1$ & 6213 & 7754 & $\mathrm{ATT}$ & TAA & $\mathrm{H}$ & 1542 \\
\hline $\operatorname{trnS2(tga)}$ & 7764 & 7832 & & & $L$ & 69 \\
\hline $\operatorname{trnD}(g t c)$ & 7839 & 7907 & & & $\mathrm{H}$ & 69 \\
\hline $\operatorname{cox} 2$ & 7908 & 8588 & ATG & TAA & $\mathrm{H}$ & 681 \\
\hline trnK(ttt) & 8595 & 8662 & & & $\mathrm{H}$ & 68 \\
\hline atp8 & 8664 & 8861 & ATG & TAA & $\mathrm{H}$ & 198 \\
\hline atp6 & 8825 & 9499 & ATG & TAA & $\mathrm{H}$ & 675 \\
\hline $\operatorname{cox} 3$ & 9505 & 10287 & ATG & TAG & $\mathrm{H}$ & 783 \\
\hline $\operatorname{trnG}(\mathrm{tcc})$ & 10289 & 10357 & & & $\mathrm{H}$ & 69 \\
\hline nad3 & 10343 & 10702 & ATC & TAG & $\mathrm{H}$ & 360 \\
\hline $\operatorname{trnR}(\mathrm{tcg})$ & 10705 & 10773 & & & $\mathrm{H}$ & 69 \\
\hline nad4l & 10774 & 11067 & ATG & TAA & $\mathrm{H}$ & 294 \\
\hline nad4 & 11064 & 12431 & ATG & TA & $\mathrm{H}$ & 1368 \\
\hline trnH(gtg) & 12442 & 12510 & & & $\mathrm{H}$ & 69 \\
\hline $\operatorname{trnS1}(\mathrm{gct})$ & 12511 & 12569 & & & $\mathrm{H}$ & 59 \\
\hline trnL1 (tag) & 12570 & 12639 & & & $\mathrm{H}$ & 70 \\
\hline nad5 & 12631 & 14445 & ATA & TAA & $\mathrm{H}$ & 1815 \\
\hline nad6 & 14450 & 14974 & $\mathrm{ATT}$ & TAA & $L$ & 525 \\
\hline $\operatorname{trn} E(t t c)$ & 14972 & 15040 & & & $L$ & 69 \\
\hline Cob & 15044 & 16177 & ATG & AGA & $\mathrm{H}$ & 1134 \\
\hline $\operatorname{trn} T(\operatorname{tgt})$ & 16184 & 16253 & & & $\mathrm{H}$ & 70 \\
\hline $\operatorname{trn} P(\operatorname{tgg})$ & 16254 & 16320 & & & $L$ & 67 \\
\hline
\end{tabular}

heteroplasmic. It is varied in terms of repeat numbers and motif among Felidae species (Table 3) [26]. When there are repeats in the genome longer than the read length, it is important to confirm NGS data with capillary sequencing. Here, RS-2 and RS-3 repeats have longer region than read length of Ion Torrent PGM. Hence RS-2 and RS-3 were validated with capillary sequencing and capillary data (RS2 and RS3 repeats) was replaced in original genome obtained from NGS. Conserved sequence blocks (CSB-2 and CSB-3) are in HVS2. CSB-1 is in the CCR, which is located between RS-2 and RS-3. CR of P. leo persica comprises 1,603 bp and it contains origin of heavy chain replication. The capillary data of RS2 and RS3 repeats was submitted to TRA (Trace archive Id: TR-16480).

\section{Phylogenetic analyses based on gene cluster}

Phylogenetic analyses was carried out on the basis of partial [27] and full gene sequences of $12 \mathrm{~S}$ rRNA, 16S rRNA, ND2, ND4, ND5, ATP8 and Cyt b using ML, MP methods (Figure 4). The monophyly of the genus Panthera, including P. leo persica, Uncia uncia, Panthera pardus, Panthera tigris amoyensis, Panthera tigris, and Neofelis nebulosa was clearly depicted. Results demonstrate 100\% bootstrap value in ML method and 99\% in MP method, using full gene sequences of $P$. leo persica (Figure 4A). Previously sequenced Panthera leo partial genes formed node with Uncia uncia with $96 \%$ bootstrap value in ML method and $88 \%$ in MP method (Figure 4B). This study strongly supports that $P$. leo persica is a sister species of $P$. pardus, than of $U$. uncia, as earlier reported [27]. N. nebulosa was forming distinct branch. $P$. tigris and $P$. tigris amoyensis being same species, formed different branch in the Panthera node while $U$. uncia was placed in the lineage between tiger and lion-leopard node.

\section{Estimates of divergence times}

The ML and Bayesian analyses based on 11 complete mitochondrial genomes, excluding control region yielded the identical tree topology supported by high bootstrap value (above 90\%, Figure 5) and high posterior probabilities (above 0.97, Figure 5). Uncorrelated lognormal relaxed clock (Figure 5) and strict molecular clock model (Additional file 1: Figure S1) were studied to estimate divergence times. Data of uncorrelated lognormal relaxed clock were considered for lineage specific rate heterogeneity. Divergence time was estimated using single calibration point at 10.78 mya for Felidae individuals, assuming common ancestor between genus Panthera and other Felinae species $[28,29]$. BEAST analysis suggested divergence time of Felidae individual was 9.62 mya (Figure 5) from the common ancestor. The divergence of $P$. leo persica was estimated 2.96 mya from the closely related species P. pardus (ML, 98\%; Bayesian, 1.00). Divergence of other individuals; $N$. nebulosa (7.09 mya), P. tigris (5.2 mya) and $U$. uncia (3.77 mya). Estimation of divergence times of genus Panthera in the present study reconfirms earlier reports [30,31]. 


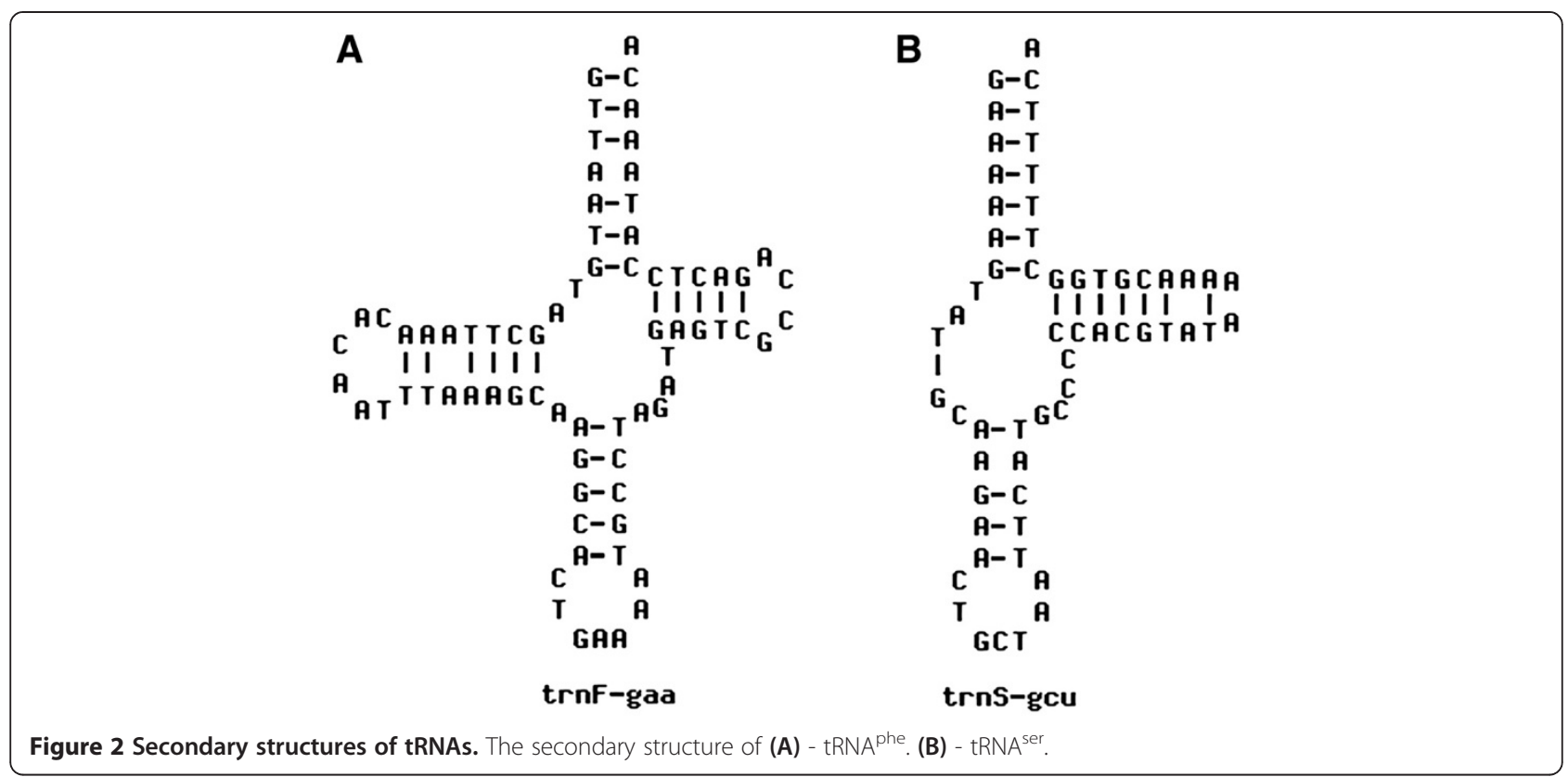

\section{Conclusion}

Present study is the first report of complete mitogenome of $P$. leo persica among all eight subspecies. The evolutionary timeline estimates of big cats based on mitogenome analysis, indicates existence of common ancestor of $P$. leo and $P$. pardus 2.96 mya in modern Piacenzian era. The significant degree of genetic differentiation of Asiatic lion from other big cats, suggest independent evolution of subspecies described as $P$. leo persica. Complete mitogenome sequence provide sufficient information to resolve the events of divergence of Felidae.

\section{Materials and methods}

\section{Sample collection and DNA extraction}

Tissue sample of a freshly dead lion cub (female, $1.5 \mathrm{yrs}$ ) with chip ID 00-06B7-22E3 was collected from Sakkarbag Zoo, Junagadh, Gujarat, India (N 21.540848, E 70.468481). The samples were immediately transferred to laboratory and stored in Allprotect Tissue Reagent (Qiagen) at $-80^{\circ} \mathrm{C}$. Tissue sample was homogenized in liquid nitrogen and DNA extraction was carried out using BioVison Mitochondrial DNA Isolation Kit (BioVision Research Products, CA, USA) following manufacturer's protocol.

\section{Sequencing}

DNA quality such as ratio of absorbance at 260/280 nm and 260/230 nm was measured using Nanophotometer (Imlpen). Qubit ${ }^{\oplus}$ 2.0 Fluorometer was used to obtain an accurate quantitation of DNA. Library was prepared using Ion Express Plus Fragment library kit (Life Technologies). Mitochondrial DNA was sheared into blunt ended fragments by enzymatic lysis using Ion Shear Plus Reagents (Life Technologies). The fragmented DNA was ligated to Ion-compatible adapters, followed by nick repair to complete the linkage between adapters and DNA inserts. Sequencing was performed using Ion Express Template

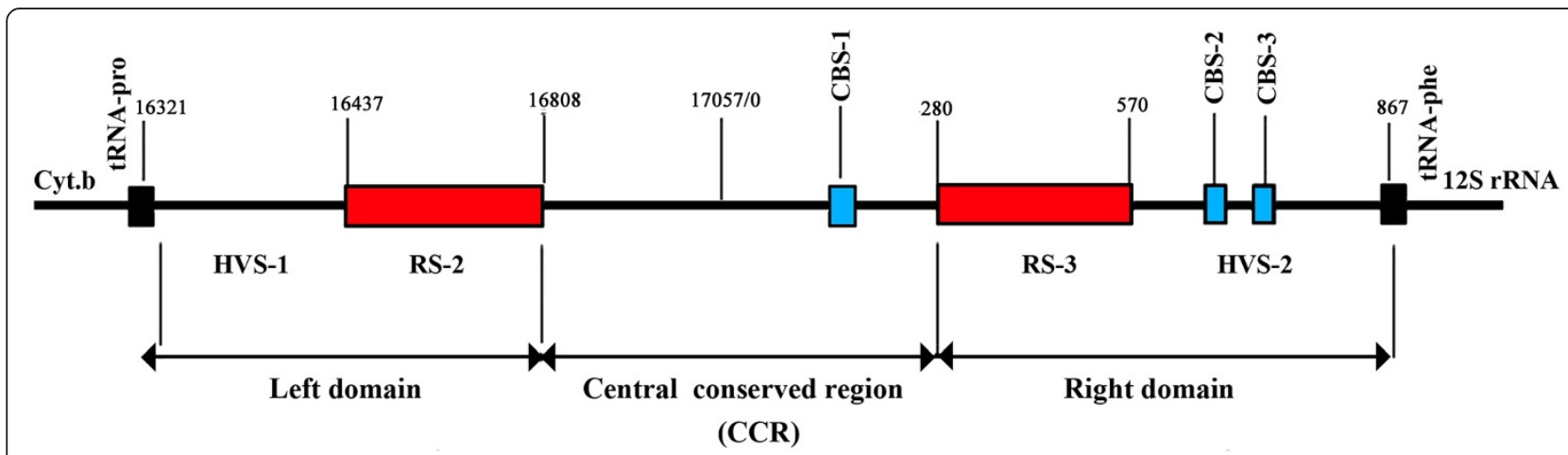

Figure 3 Structure of control region of Panthera leo persica mitogenome. Showing conserved blocks, location of repetitive sequences (RS), and other defined domains. 
Table 3 Repeat sequence comparison in Felidae family

\begin{tabular}{|c|c|c|c|c|c|}
\hline Species Name & RS2 (No. of repeats) & RS3 (No. of repeats) & RS3 motif length & RS3 motif & Genome length \\
\hline Panthera leo persica & 4.7 & 21.1 & 14 & ACACGTACACACGT & $17057 \mathrm{bp}$ \\
\hline Panthera pardus & 1.9 & 48.5 & 8 & ACACGTAC & $16964 \mathrm{bp}$ \\
\hline Uncia uncial & 2 & 12.4 & 14 & TACACGTACACGTA & $16773 \mathrm{bp}$ \\
\hline Panthera tigris & 2 & 47.4 & 8 & CACGTATA & $16990 \mathrm{bp}$ \\
\hline Panthera tigris amoyensis & 2.1 & 47.5 & 8 & ACACGTAC & $17001 \mathrm{bp}$ \\
\hline Neofelis nebulosa & Not found & 37.7 & 6 & ACACGT & $16844 \mathrm{bp}$ \\
\hline Felis catus & 3.2 & 36.6 & 8 & ACACGTAC & $17009 \mathrm{bp}$ \\
\hline Prionailurus bengalensis euptilurus & 3.1 & 37.4 & 8 & CACGTATA & $16990 \mathrm{bp}$ \\
\hline Lynx rufus & 3.8 & 43.5 & 8 & ACACGTAC & 17056 bp \\
\hline Acinonyx jubatus & 3.5 & 50.2 & 6 & CGTACA & 17047 bp \\
\hline Puma concolor & 4.7 & 45.6 & 8 & TACACGTA & 17153 bp \\
\hline
\end{tabular}

RS2 motif sequence remains conserved, while RS3 motif varies in Felidae family.

300 chemistry (Life Technologies) on 316 chip following manufacturer's protocol.

Capillary Sequencing of D-loop region was performed to validate Ion Torrent data. PCR of D-loop was performed using forward (5'TCAAGGAAGAAGCAAT AGCC 3') and reverse (5'GGATTGTTGGGCGTGTAAA 3 ') primers. Further sequencing was carried out using PCR primers and internal primer (5'TATTCTCTATG
CGGGGGTTC 3') using Big Dye v3.1 Chemistry (Applied Biosystems) on 3500 Genetic Analyzer (Applied Biosystems) following manufacturer's protocol.

\section{Data analysis}

Reads longer than $100 \mathrm{bp}$ were mapped to the $P$. pardus reference mitogenome [GenBank: NC_010641], using CLC Genomic Workbench 5 [32]. Assembled

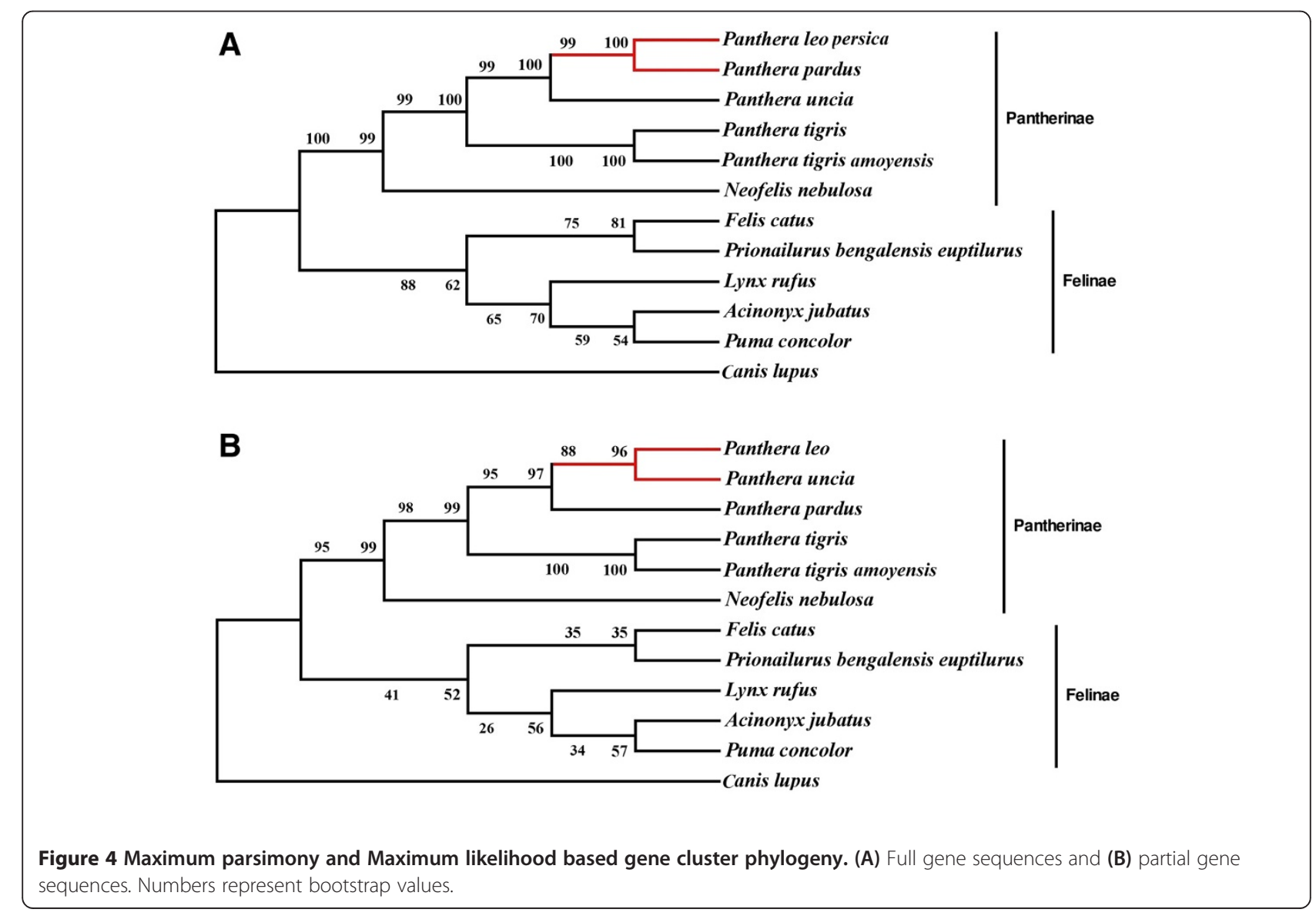




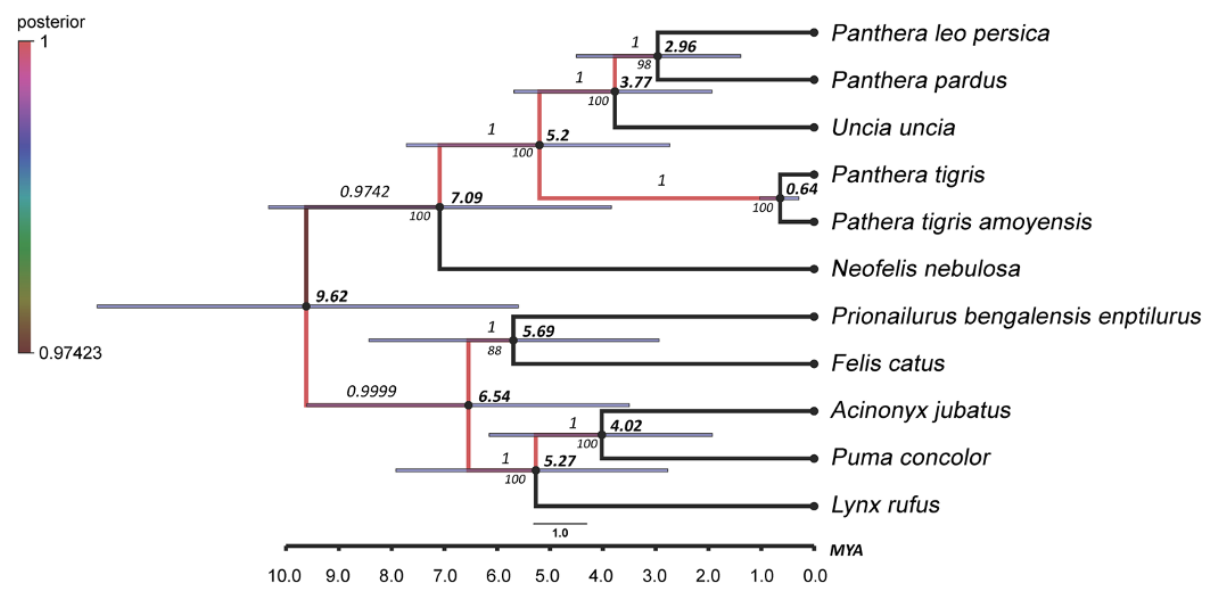

Figure 5 Phylogenetic tree and divergence time estimates. ML and Bayesian analysis based on whole mitogenomes. Numbers above the nodes represent posterior probabilities and numbers below the nodes are bootstrap values. Bold numbers represent estimated divergence times. The $95 \%$ highest posterior density estimates for each clade are presented by bars.

mitogenome was annotated, using MITOS online mitochondrial genome annotation server [14]. Control region repeats RS-2 and RS-3 were identified using Tandem Repeats Finder [33].

\section{Molecular phylogenetic analysis}

Phylogeny of $P$. leo was constructed based on partial and full mitochondrial gene cluster (12S rRNA+16S rRNA +ND2+ND4+ND5+ATP8+Cyt b). Partial P. leo genes having accession number A79300, AF006457, AY170043, AY634398, AF006458, S79302 and DQ899945 [27] were retrieved from NCBI. Full sequences of above same genes of $P$. leo persica were compared with gene sequences of $P$. uncia [NC_010638], P. pardus [NC_010641], P. tigris [NC_010642], P. tigris amoyensis [NC_014770], N. nebulosa [NC_008450], A. jubatus [NC_005212], P. concolor [NC_016470], L. rufus [NC_014456], F. catus [NC_001700] and $P$. bengalensis euptilurus [NC_016189] obtained from NCBI organelle genome resource (Table 1). The data was subjected to Maximum likelihood (ML) and Maximum parsimony (MP) methods using MEGA v5.05 software package [34] to establish phylogenetic relationship.

These seven genes were concatenated and multiple alignment was carried out using ClustalW built-in MEGA. The number of bootstrap replicates was set to 1000 and phylogeny was constructed using Hasegawa-Kishino-Yano model, determined by MEGA 5.05 as the best fitting nucleotide substitution model.

\section{Divergence time estimation}

Multiple sequence alignment of genomes was carried out and phylogenetic tree was constructed using $\mathrm{HKY}+\mathrm{G}+\mathrm{T}$ substitution model at 1000 bootstrap replicates. Divergence times were estimated between species using
Bayesian evolutionary analysis by sampling trees (BEAST v1.7.1) software [35]. Markov Chain Monte Carlo (MCMC) procedure was used within a Bayesian analysis framework to estimate posterior distributions of evolutionary rates and divergence times. These analyses were performed using DNA sequence alignment of complete mitogenomes, excluding control region. Divergence times were estimated using an uncorrelated lognormal relaxed clock to account for lineage-specific rate heterogeneity as well as using strict molecular clock model (Additional file 1: Figure S1). Bayesian MCMC analyses in BEAST were performed using HKY model of evolution and gamma+ invariant rate heterogeneity models. Divergences were estimated under a Yule speciation process that is generally more appropriate when considering sequences from different species [36]. Monophyletic constraints were imposed for the node to calibrate evolutionary rates. Normal priors were used for the times to the most recent common ancestor (TMRCA) of Pantherinae and Felinae is (mean $10.78 \pm 1.87$ mya), based on the posterior distributions obtained [29].

Simultaneous Markov chains were run for 10,000,000 generations, sampling every 1000 steps. Thus the ".trees" file will contain 10,000 trees and after removing $10 \%$ burnin, tree was annotated using TreeAnnotator. Posterior probability limit was set to zero to annotate all nodes. Maximum clade credibility tree was selected for target tree to find highest product of the posterior probability for all nodes. The phylogenetic tree graphic was generated using FigTree v1.3.1 [37].

\section{GenBank accession number}

The complete mitogenome sequence with gene prediction and functional annotation was submitted to GenBank with accession no. KC834784. The raw 
sequence data generated from Ion Torrent was submitted to SRA with accession no SRR821548. Mitochondrial D-loop sequence was submitted to GenBank with accession no. KC917264.

\section{Additional file}

Additional file 1: Figure S1. Phylogenetic tree and divergence time estimates based on strict molecular clock model. Numbers above the nodes represent posterior probabilities. Numbers at the node represent estimated divergence times [FigTree file is also uploaded as "S1FigTree"]

\section{Abbreviations}

DHU arm: Dihydrouracil arm; HVS: Hypervariable sequence; ML: Maximum likelihood; MP: Maximum parsimony; Mya: Million years ago; NGS: Next generation sequencing.

\section{Competing interests}

The authors declare they have no competing interests.

\section{Authors' contributions}

AKS, SBB and MNJ conceptualized this study, ASP, OVP, RPP and FPJ carried out the mtDNA extraction, SBB, MNJ, RVP, ASP, AS and RPP performed the sequencing, SBB and SMD carried out the mitogenome assembly, annotations and phylogenetic studies. SBB and team drafted the manuscript. All authors read and approved the final manuscript.

\section{Acknowledgements}

This research was majorly supported by Gujarat State Biotechnology Mission, Department of Science \& Technology, Government of Gujarat, INDIA under The LeoGen pilot project. Authors are thankful to Shri Ravi Saxena, IAS, Additional Chief Secretary, Department of Science \& Technology,

Government of Gujarat for providing full support and administrative freedom for Gujarat State Biotechnology Mission for undertaking this project. Authors are also thankful to Gujarat State Forest Department for providing biomaterials and part financial support. Authors are specially thankful to Dr. S. K. Nanda, IAS, Principal Secretary, Forest \& Environment, Government of Gujarat, Shri Pradeep Khanna, IFS, Principal Chief Conservator of Forest \& Head of Forest Force, Gujarat, Shri S. K. Goyal, IFS, Principal Chief Conservator of Forest, Wildlife \& Chief Wildlife Warden, Gujarat who facilitated in getting the necessary permission from Ministry of Forest \& Environment, Government of India, Government of Gujarat. Authors are also thankful to Shri M. M. Sharma, IFS, Ex-chief Conservator of Forest, Junagadh Wildlife Circle, Shri R. L. Meena, IFS, Chief Conservator of Forest, Wildlife, Junagadh, Dr. Sandeep Kumar, IFS, Deputy Conservator of Forest, Sasan and Shri V. J. Rana, Director, Shakkarbaug Zoo for providing all help and co-operation in enabling the availability of bio-material from different areas. Authors are thankful to the field staff and veterinarians, involved in collection of samples.

Received: 25 June 2012 Accepted: 12 August 2013

Published: 23 August 2013

\section{References}

1. Warren EJ, Peter AD, Janice SM, Stephen JO: Resolution of recent radiations within three evolutionary lineages of felidae using mitochondrial restriction fragment length polymorphism variation. J Mamm Evol 1996, 3(2):97-120.

2. Seung-Jin S, Tiffani LW: Big cat phylogenies, consensus trees, and computational thinking. J Comput Bio/ 2011, 18(7):895-906.

3. Burger J, Rosendahl W, Loreille O, Hemmer H, Eriksson T, Götherström A, Hiller J, Collins MJ, Wess T, Alt KW: Molecular phylogeny of the extinct cave lion Panthera leo persica spelaea. Mol Phylogenet Evol 2004, 30(3):841-849.

4. $\quad$ Singh HS, Gibson L: A conservation success story in the otherwise dire megafauna extinction crisis: the Asiatic lion (Panthera leo persica) of Gir forest. Biol Conserv 2011, 144(5):1753-1757.

5. Stephen JO, Janice SM, Craig P, Lawrence H, Valerius D, Paul J, Janis O, David EW, Mitchell B: Biochemical genetic variation in geographic isolates of African and Asiatic lions. Natl Geogr Res 1987, 3(1):114-124.
6. Singh A, Shailaja A, Singh A, Shailaja A, Gaur L, Singh V: Development and characterization of novel microsatellite markers in the Asiatic lion (Panthera leo persica). Mol Ecol Resour 2002, 2(4):542-554.

7. Dianne NJ, William SM, Stephens JC, O'Brien SJ: Molecular phylogeny of mitochondrial cytochrome $b$ and $12 \mathrm{~S}$ rRNA sequences in the Felidae. Mol Phylogenet Evol 1995, 12(4):690-707.

8. Michelle YM, Deborah AM: Phylogeny and speciation of felids. Cladistics 2000, 16(2):232-253.

9. Jae-Heup K, Eizirik E, O'Brien SJ, Johnson WE: Structure and patterns of sequence variation in the mitochondrial DNA control region of the great cats. Mitochondr DNA 2001, 1(3):279-292.

10. Zhang W, Zhang Z, Shen F, Hou R, Lv X, Yue B: Highly conserved D-loop-like nuclear mitochondrial sequences (Numts) in tiger (Panthera tigris). J Genet 2006, 85(2):107-116.

11. Boore $J$, Macey JR, Medina M: Sequencing and comparing whole mitochondrial genomes of animals. Methods Enzymol 2005, 395:311-348.

12. Hebert PD, Cywinska A, Ball SL, deWaard JR: Biological identifications through DNA barcodes. Proc Biol Sci 2003, 270(1512):313-322.

13. Davis BW, Li G, Murphy WJ: Supermatrix and species tree methods resolve phylogenetic relationships within the big cats, panthera (carnivora: Felidae). Mol Phylogenet Evol 2010, 56(1):64-76.

14. MITOS. [http://mitos.bioinf.uni-leipzig.de]

15. Kim KS, Seong EL, Ho WJ, Ji HH: The complete nucleotide sequence of the domestic dog (Canis familiariz) mitochondrial genome. Mol Phylogenet Evol 1998, 10(2):210-220.

16. Ursing BM, Arnason U: The complete mitochondrial DNA sequence of the pig (Sus scrofa). J Mol Evol 1998, 47(3):302-306.

17. Gissi C, Gullberg A, Arnason U: The complete mitochondrial DNA sequence of the rabbit (Oryctolagus cuniculus). Genomics 1998, 50(2):161-169.

18. Sumida M, Kanamori Y, Kaneda H, Kato Y, Nishioka M, Hasegawa M, Yonekawa $\mathrm{H}$ : Complete nucleotide sequence and gene rearrangement of the mitochondrial genome of the Japanese pond frog Rana nigromaculata. Genes Genet Syst 2001, 76(5):311-325

19. Wu XB, Wang YQ, Zhou KY, Zhu WQ, Nie JS, Wang CL: Complete mitochondrial DNA sequence of Chinese alligator, Alligator sinensis, and phylogeny of crocodiles. Chin Sci Bull 2003, 48(19):2050-2054.

20. Douglas DA, Gower DJ: Snake mitochondrial genomes: phylogenetic relationships and implications of extended taxon sampling for interpretations of mitogenomic evolution. BMC Genomics 2010, 11:14.

21. Sun Y, Ma F, Xiao B, Zheng JJ, Yuan XD, Tang MQ, Wang L, Yu YF, Li QW: The complete mitochondrial genomes sequences of Asio flammeus and Asio otus and comparativeanalysis. Sci China Ser C Life Sci 2004, 47(6):510-520.

22. Hu M, Chilton NB, Gasser RB: The mitochondrial genome of Strongyloides stercoralis (Nematoda) - idiosyncratic gene order and evolutionary implications. Int J Parasitol 2003, 33(12):1393-1408.

23. Man Z, Yishu W, Peng Y, Xiaobing W: Crocodilian phylogeny inferred from twelve mitochondrial protein-coding genes, with new complete mitochondrial genomic sequences for Crocodylus acutus and Crocodylus novaeguineae. Mol Phylogenet Evol 2011, 60(2011):62-67.

24. Wei $L$, Xiaobing $E$, Jiang $Z$ : The complete mitochondrial genome structure of snow leopard Panthera uncia. Mol Biol Rep 2009, 36(3):871-878.

25. Wu X, Yan P, Hu L, Su X, Jiang Z: Complete nucleotide sequences and gene organization of mitochondrial genome of Bufo gargarizans. Mitochondrion 2006, 6(4):186-193.

26. Jae-Heup K, Eizirik E, O'Brien SJ, Johnson WE: Structure and patterns of sequence variation in the mitochondrial DNA control region of the great cats. Mitochondrion 2001, 1(3):279-292.

27. Lei WEl, XiaoBing WU, LiXin ZHU, ZhiGang JIANG: Mitogenomic analysis of the genus Panthera. Sci China Life Sci 2011, 54(10):917-930.

28. O'Brien SJ, Johnson WE: The evolution of cats. Genomic paw prints in the DNA of the world's wild cats have clarified the cat family tree and uncovered several remarkable migrations in their past. Sci Am 2007, 297(1):68-75.

29. Johnson WE, Eizirik E, Pecon-Slattery J, Murphy WJ, Antunes A, Teeling E, O'Brien SJ: The late miocene radiation of modern felidae: a genetic assessment. Science 2006, 311(5757):73-77.

30. Janczewski DN, Modi WS, Stephens JC: Molecular evolution of mitochondrial 12S RNA and cytochrome b sequences in the Pantherine lineage of Felidae. Mol Biol Evol 1995, 12(4):690-707.

31. Frazer-Abel AA, Hagerman PJ: Determination of the angle between the acceptor and anticodon stems of a truncated mitochondrial tRNA. Mol Biol 1999, 85(2):581-593. 
32. CLC Genomics Workbench v 5.0. http://www.clcbio.com/products/clcgenomics-workbench/.

33. Benson G: Tandem repeats finder: a program to analyze DNA sequences. Nucleic Acids Res 1999, 27(2):573-580.

34. Tamura K, Peterson D, Peterson N, Stecher G, Nei M, Kumar S: MEGA5: molecular evolutionary genetics analysis using maximum likelihood, evolutionary distance, and maximum parsimony methods. Mol Biol Evol 2011, 28(10):2731-2739.

35. Drummond AJ, Rambaut A: BEAST: Bayesian evolutionary analysis by sampling trees. BMC Evol Biol 2007, 7:214

36. Anne CS, Fabia UB, Laura SK, George HP, Evan T, Hsiuman L, Sudhir K: More reliable estimates of divergence times in Pan using complete mtDNA sequences and accounting for population structure. Philos Trans $R$ Soc Lond B Biol Sci 2010, 365(1556):3277-3288

37. FigTree v1.3. http://tree.bio.ed.ac.uk/software/figtree/.

doi:10.1186/1471-2164-14-572

Cite this article as: Bagatharia et al:: Complete mitogenome of asiatic lion resolves phylogenetic status within Panthera. BMC Genomics 2013 14:572.

\section{Submit your next manuscript to BioMed Central and take full advantage of:}

- Convenient online submission

- Thorough peer review

- No space constraints or color figure charges

- Immediate publication on acceptance

- Inclusion in PubMed, CAS, Scopus and Google Scholar

- Research which is freely available for redistribution 